\title{
Community Health Center
}

National Cancer Institute

\section{Source}

National Cancer Institute. Community Health Center. NCI Thesaurus. Code C16454.

Community Health Centers ( $\mathrm{CHCs}$ ) are private, non-profit organizations that directly or indirectly (through contracts and cooperative agreements) provide primary health services and related services to residents of a defined geographic area that is medically undeserved. Community health centers have a three-fold mission. First, CHCs aim to improve access to care for low income, underserved, vulnerable populations. They are required to be located in medically-underserved rural and urban areas, and within those communities, they serve those with limited access to more mainstream health care. Second, CHCs provide a fully comprehensive range of primary care services, including "enabling" or support services. Third, they involve the community in both the management and governance of the center. 